\title{
In focus in HCB: new histochemical insights into mammalian gametogenesis
}

\author{
Yoshitaka Hishikawa ${ }^{1} \cdot$ Toshihiro Takizawa $^{2} \cdot$ Takehiko Koji $^{3}$
}

Published online: 1 March 2022

(c) The Author(s), under exclusive licence to Springer-Verlag GmbH Germany, part of Springer Nature 2022

During the past decade, regeneration science of cells, organs, and individuals has been a big topic and continues to develop at an ever faster pace, implying that it could enable the replacement of damaged cells and organs with regenerated ones or rejuvenation by reprogramming the differentiation states or more strictly by artificial manipulation of epigenomes. However, in the natural process of mammalian development, such life events are supposed to be triggered only by fertilization of sperm and eggs, the whole story of which is known as reproduction. Therefore, the understanding of mammalian gametogenesis should be principally important, perhaps by providing essential clues to solve various current problems, and moreover provide highly basic knowledge to evolve regeneration science in the right way. The process of gametogenesis is a well-ordered and continuous progression of events in the testis and ovary, and the analysis of their regulatory mechanisms woud require histochemical approaches to permit us to analyze the expression of proteins and their transcripts in individual cells in situ, because of closed topographical localization of cells of various differentiation stages. In fact, we have shown that during both spermatogenesis and oogenesis, the expression of genetic and epigenetic factors fluctuates significantly and is involved in the regulation of germ cell

Takehiko Koji

tkoji@nagasaki-u.ac.jp

Yoshitaka Hishikawa

yhishi@med.miyazaki-u.ac.jp

Toshihiro Takizawa

t-takizawa@nms.ac.jp

1 Department of Anatomy, Histochemistry and Cell Biology, Faculty of Medicine, University of Miyazaki, Miyazaki 889-1692, Japan

2 Department of Molecular Medicine and Anatomy, Nippon Medical School, Tokyo 113-8602, Japan

3 Office of Research Initiative and Development, Nagasaki University, Nagasaki 852-8521, Japan kinetics such as proliferation, differentiation, and death in a complicated manner. For example, in germ cell apoptosis alone we encountered a variety of cell-type-specific phenomena (for spermatogenesis, Wang et al. 1998; Koji et al. 2001; Dai et al. 2015; Koji and Shibata 2020; and for oogenesis, Hakuno et al. 1996; Liu et al. 2018). Here, we have attempted to organize a Special Issue entitled "New histochemical insights into mammalian gametogenesis," to promote our knowledge of recent progress in the understanding of physiological and pathological phenomena related to mammalian gametogenesis.

\section{Male part}

In recent decades, sperm count, concentration, and quality in semen have decreased in men in developed countries, and the causes are multifactorial and complex. The accumulation of basic knowledge regarding the microenvironment of spermatogenesis and maturation will be helpful to solve these problems. In this special issue, Miyaso et al. (2022) review the microenvironment of the male reproductive tissues and its control, such as genetic and epigenetic control of spermatogenesis, the blood-testis barrier, and neuroendocrine-immune control. Wakayama et al. (2022) introduce a simplified flowchart to determine the stages of mouse spermatogenesis. Based on a fluorescence approach, intra-acrosomal glycoprotein of male germ cells is detected by lectin histochemistry using peanut agglutinin. Moreover, the usefulness of specific markers for male germ cells and somatic cells in the testis is summarized. This approach is opening new possibilities in quantitative evaluation of spermatogenesis.

Based on an in vitro organ culture system, Okugi et al. (2022) found temperature-dependent germ cell loss which mimics cryptorchidism. This experimentally induced cryptorchidism model system has several advantages as compared with classical surgically induced cryptorchidism, such 
as easy monitoring of the microenvironment and temperature, which are crucial factors for spermatogenesis. This model may reveal the precise mechanisms of cryptorchidism and new knowledge of meiosis.

Nagahori et al. (2022) established a model of immunologic male infertility using $\mathrm{G}$ protein-coupled receptor kinase interacting protein-1 in mice. Successful generation of experimental autoimmune orchitis will be helpful to understand the pathogenesis of immunologic male infertility, and it could provide a basis for the development of novel diagnosis and therapy for autoimmunity-based disturbance of spermatogenesis. Omotehara et al. (2022) studied the basic morphogenesis of the male genital tract between the testis and mesonephros and compared this in mammals, avian species, and frogs. Three-dimensional construction analysis revealed that these species share basic morphogenesis, such as the sperm transport pathway that develops between the testis cords and the cluster of rete cells.

\section{Female part}

In female gametogenesis (oogenesis), ovarian folliculogenesis is a dynamic and complex process of primordial follicle formation, transformation of primordial follicles to Graafian follicles, and corpus luteum formation after ovulation. Although the molecular mechanisms underlying follicular development are still unclear, factors (e.g., genes, signaling molecules, and targets) that control the different stages of folliculogenesis continue to be identified. Tanimoto et al. (2021) review genetics, endocrinology, and in vitro investigations of factors that can affect follicle formation in mammals. A current in vitro system is capable of achieving the entire process of oogenesis for recapitulating oogenesis. The in vitro system provides new insight into the contribution of an endogenous anti-estrogenic factor alpha-fetoprotein that inhibits estrogen-induced anti-Müllerian hormone to follicle formation in vivo.

Female reproductive function and its life span are regulated by the number of stockpiled primordial follicles in the ovary and the quality of oocytes in the follicles. Watanabe et al. (2022) investigated the retention of ovulatory capacity in middle-aged cystine-glutamate transporter (xCT)-knockout $(\mathrm{KO})$ mice. $\mathrm{xCT}$ protects cells from oxidative stress. $\mathrm{xCT}-\mathrm{KO}$ suppressed the recruitment of primordial follicles to primary follicles partially via the Akt signaling pathway during the neonatal period, resulting in fertility preservation in late-reproductive-age mice.

High-mobility group box 2 (Hmgb2) is a chromatinassociated protein that is involved in the regulation of transcription. Yamaguma et al. (2022) demonstrated the functional role of $\mathrm{Hmgb} 2$ in mouse ovarian folliculogenesis using Hmgb2-KO mice, where Hmgb2-KO caused ovarian atrophy, with a significant decrease in germ cell numbers and progressive fibrosis. Hmgb2 may play an important role in follicular development and maintenance in the mouse ovary.

Apart from ovarian follicular development, oviductal fluid in the lumen of the oviduct provides an important milieu for gamete maturation and fertilization. Zhao et al. (2022) reviewed the identification and characterization of oviduct-specific glycoprotein (OVGP1) and its functions in various mammalian species, including humans. OVGP1 plays a key role in sperm capacitation, fertilization, and early embryo development. Consequently, the production of recombinant mammalian OVGP1 will accelerate research on the biological function and the molecular mechanism of OVGP1 in mammalian fertilization.

Finally, we hope that the papers of this Special Issue will appeal to readers who are working or are interested in the fields of reproduction and regeneration.

\section{References}

Dai L, Endo D, Akiyama N, Yamamoto-Fukuda T, Koji T (2015) Aberrant levels of histone $\mathrm{H} 3$ acetylation induce spermatid anomaly in mouse testis. Histochem Cell Biol 143:209-224. https://doi.org/ 10.1007/s00418-014-1283-1

Hakuno N, Koji T, Yano T, Kobayashi N, Tsutsumi O, Taketani Y, Nakane PK (1996) Fas/APO-1/CD95 system as a mediator of granulosa cell apoptosis in ovarian follicle atresia. Endocrinology 137:1938-1948. https://doi.org/10.1210/endo.137.5.8612534

Koji T, Shibata Y (2020) Global changes in epigenomes during mouse spermatogenesis: possible relation to germ cell apoptosis. Histochem Cell Biol 154:123-134. https://doi.org/10.1007/ s00418-020-01900-x

Koji T, Hishikawa Y, Ando H, Nakanishi Y, Kobayashi N (2001) Expression of Fas and Fas ligand in normal and ischemia-reperfusion testes: involvement of the Fas system in the induction of germ cell apoptosis in the damaged mouse testis. Biol Reprod 64:946-954. https://doi.org/10.1095/biolreprod64.3.946

Liu J, Zhang W, Wu Z, Dai L, Koji T (2018) Analysis of changes in DNA methylation of oocytes and granulosa cells by HELMET during folliculogenesis in mouse ovary. Acta Histochem Cytochem 51:93-100. https://doi.org/10.1267/ahc.17039

Miyaso H, Ogawa Y, Itoh M (2022) Microenvironment for the spermatogenesis and the sperm maturation. Histochem Cell Biol. https:// doi.org/10.1007/s00418-021-02071-Z

Nagahori K, Kuramasu M, Kawata S, Yakura T, Li Z, Hirai S, Qu $\mathrm{N}$, Itoh M (2022) GIT1 is an untolerized autoantigen involved in immunologic disturbance of spermatogenesis. Histochem Cell Biol. https://doi.org/10.1007/s00418-021-02061-1

Okugi K, Kuwahara N, Yanome N, Yamada K, Ito T, Takano A, Ohira S, Nagai A, Tone S (2022) An in vitro system for experimentallyinduced cryptorchidism. Histochem Cell Biol. https://doi.org/10. 1007/s00418-022-02078-0

Omotehara T, Nakata H, Nagahori K, Itoh M (2022) Comparative anatomy on the development of sperm transporting pathway between the testis and mesonephros. Histochem Cell Biol. https://doi.org/ 10.1007/s00418-021-02057-x

Tanimoto R, Yoshida K, Ikeda S, Obata Y (2021) Insights into in vivo follicle formation: a review of in vitro systems. Histochem Cell Biol. https://doi.org/10.1007/s00418-021-02058-w 
Wakayama T, Yokota S, Noguchi K, Sugawara T, Sonoda K, Wanta A (2022) Quantitative evaluation of spermatogenesis by histochemistry. Histochem Cell Biol. https://doi.org/10.1007/ s00418-022-02080-6

Wang RA, Nakane PK, Koji T (1998) Autonomous cell death of mouse male germ cells during fetal and postnatal period. Biol Reprod 58:1250-1256. https://doi.org/10.1095/biolreprod58.5.1250

Watanabe R, Takano T, Sasaki S, Obara M, Umeno K, Sato H, Kimura $\mathrm{N}$ (2022) Retention of a higher fertility depending on ovarian follicle reserve in cystine-glutamate transporter gene deficient mice. Histochem Cell Biol. https://doi.org/10.1007/s00418-022-02077-1

Yamaguma Y, Sugita N, Choijookhuu N, Yano K, Lee D, Ikenoue M, Fidya SS, Ishizuka T, Tanaka M, Yamashita Y, Chosa E, Tanuguchi N, Hishikawa Y (2022) Crucial role of high-mobility group box 2 in mouse ovarian follicular development through estrogen receptor beta. Histochem Cell Biol. https://doi.org/10.1007/ s00418-022-02074-4

Zhao Y, Vanderkooi S, Kan FWK (2022) The role of oviduct-specific glycoprotein (OVGP1) in modulating biological functions of gametes and embryos. Histochem Cell Biol. https://doi.org/10.1007/ s00418-021-02065-x

Publisher's Note Springer Nature remains neutral with regard to jurisdictional claims in published maps and institutional affiliations. 